\title{
A REPRESENTAÇÃo DA FUNÇÃO PATERNA PARA INSTITUIÇÔES DE AUXÍLIO A ADOLESCENTES EM CONFLITO COM A LEI
}

\author{
Ricardo Alves da Silva* \\ Sandra Maria Baccara Araújo**
}

\section{Resumo}

No presente artigo articula-se a importância da função paterna para o desenvolvimento da criança e do adolescente e como a falta dessa funçáo faz o jovem buscar alguém que a exerça. Muitas vezes, durante essa busca, os adolescentes cometem atos infracionais que os levam a entrar em conflito com a lei e, consequentemente, entrar em contato com os atores da justiça, que podem representar os limites que esses adolescentes procuraram. A metodologia adotada é a epistemologia qualitativa, que enfoca a análise da entrevista participativa. Para tal análise foram entrevistados atores da justiça envolvidos nos processos com adolescentes em conflito com a lei que discutiram a carência no Distrito Federal em relação a políticas públicas e a urgência de mobilização da sociedade para se ter resultados favoráveis no desenvolvimento do trabalho com os adolescentes em conflito com a lei.

Palavras-chave: função paterna; adolescente em conflito com a lei; atores da justiça.

* Centro de Estudo, Pesquisas e Atendimento Global da Infância e Adolescência. Brasília/ DF. Brasil. E-mail: ricardoalves@cepagia.com.br.

** Departamento de Psicologia Clínica do Instituto de Psicologia da Universidade de Brasília. Brasília/DF. Brasil. E-mail: sbaccara@terra.com.br. 


\begin{abstract}
THE REPRESENTATION OF PATERNAL FUNCTION FOR CIVIL INSTITUTIONS AID FOR ADOLESCENTS IN CONFLICT WITH THE LAW

In this article articulates the importance of paternal role for the development of children and adolescents, and the lack of this function makes the young look for one that carries. Many times during this search, the adolescents commit illegal acts, leading them into conflict with the law and therefore contact with the actors of justice, which may represent the limits that these adolescents sought. The methodology adopted is qualitative epistemology, which focuses on the participatory analysis of the interview. For this analysis were interviewed actors involved in the processes of justice with adolescents in conflict with the law where they discussed the shortfall in the Federal District in relation to public policy and the urgency of mobilizing society to have favorable results in the development of work with adolescents in conflict with the law.

Keywords: paternal function; teenager in conflict with the law; justice actors.
\end{abstract}

\title{
Resumen
}

LA REPRESENTACIÓN DE LA FUNCIÓN PATERNA PARA INSTITUCIONES DE AYUDA A LOS NIÑOS EN CONFLICTO CON LA LEY

En este trabajo se articula la importancia de la función paterna en el desarrollo de los niños y adolescentes, y cómo la falta de esta característica hace que los jóvenes buscan a alguien para ejercerla. A menudo, durante esta búsqueda, los adolescentes cometen infracciones que dan lugar a un conflicto con la ley y por lo tanto en contacto con los actores de la justicia, que puede representar los limites que estos adolescentes buscaban. La metodología es la epistemología cualitativa, que se centra en el análisis de la entrevista participativa. Para estas análisis fueron entrevistados los actores que participan en los procesos de la justicia con los jóvenes en conflicto con la ley, que discutieran el déficit en el Distrito Federal en materia de politica pública y la urgencia de movilizar a la sociedad para tener resultados favorables en el desarrollo del trabajo con adolescentes en conflicto con la ley.

Palabras clave: función paterna; los adolescentes en conflicto con la ley; los agentes de la justicia.

\section{Introduçáo}

Este artigo propóe estabelecer uma articulação sobre como as instituiçóes de auxílio ao adolescente em conflito com a lei executam uma função que se assemelha ao exercício da função paterna para o desenvolvimento psíquico da criança

Psic. Clin., Rio de Janeiro, vol. 25, N.I, P. 37 - 52, 2013 
e do adolescente, destacando, com base na teoria psicanalítica, as implicaçóes da ausência desta função na trajetória do jovem e em sua constituição como sujeito.

Baseando-nos na teoria psicanalítica e na importância que Winnicott (2000) dá ao conceito de limite como estruturador da criatividade, entende-se que a ausência deste impede que o adolescente pense, seja criativo e organize sua mente, pois é ele que o ajuda nesta organizaçáo.

Em uma realidade na qual os adolescentes buscam de forma desenfreada por prazer e limites por meio de atos infracionais, eles estâo frequentemente com problemas com a justiça; logo, identificar esse grito de socorro atrás dos atos cometidos por esses adolescentes ajudará a percebê-los como sujeitos e proporcionar o limite que eles tanto procuram, além de ser importante para sua organização psíquica e capacidade criativa.

\section{Fundamentação teórica}

\section{A constituição do sujeito adolescente e a importância da função paterna}

Winnicott (2000) afirma que a relação mãe-bebê só será bem exercida se houver um pai para dar segurança e apoio suficientes para ela ser uma mãe suficientemente boa. $\mathrm{O}$ autor coloca essa relaçáo mãe-bebê como sendo um espaço suficientemente bom, onde é oferecido à criança alcançar e superar em cada etapa do seu desenvolvimento as satisfaçóes, ansiedades e conflitos inatos e pertinentes.

Julien (1997) nos lembra que esse pai entra na relação mãe-bebê sendo nomeado pela própria mãe. A mãe instaura na ordem simbólica um lugar que, ocupado pelo pai, será uma fonte de formação de autoridade para a criança.

Vale ressaltar, como coloca Dor (1991), que a concepção de pai na psicanálise difere da referência de paternidade intitulada pelo senso comum. A função paterna corresponde a um lugar que foi nomeado pela máe, lugar este investido de poder legítimo e que proporciona uma intervenção estruturante. Portanto independe do sexo de quem exercer essa função, pois esse pai é universal, é uma função, não necessariamente uma pessoa. $\mathrm{O}$ pai quebra a simbiose existente entre mãe e filho e se apresenta como a lei para a criança. A função paterna, como afirma Araújo (2006), é fundamental no processo de formação do Superego, pois possibilita à criança e ao adolescente a interiorizaçáo de uma série de regras que são essenciais para sua vida social. Uma vez que é o representante da lei, o pai é o maior responsável por esse processo. 
Não estruturar esses limites e valores adequadamente faz com que o jovem tenha dificuldades de amadurecer e, como reflete Araújo (2006, p. 146) em sua pesquisa com atores da justiça, "essa dificuldade está associada à falta de referência paterna para o adolescente na família”.

Quando a criança ou adolescente encontra no pai uma fonte de suporte e limite, ele terá maior facilidade em internalizar as leis e regras que regem a sociedade. Winnicott (1982/1992, p. 184) afirma que "um pai forte capacita a criança a correr o risco, ao se pôr no caminho ou se achar lá para corrigir as coisas ou impedi-las através da sua fúria”.

Winnicott (2000) alerta que quando a lei não está internalizada pelo sujeito institui-se a destrutividade. É nesse momento que pode estar se formando um sujeito com potencial para entrar em conflito com a lei. A destrutividade ocasionada pela impossibilidade de internalização da lei, déficit esse causado pela ausência do exercício da função paterna, leva o jovem a procurar alguém que exerça essa função, e nessa procura inconsciente ele pode encontrar modelos de identificação que o afastem da norma social.

O pai ocupa um lugar onde deve exercer uma atividade interditora, que serve para organizar a vida social do filho. Esse lugar se dá através da função paterna: através do exercício desta função a criança internaliza a lei e os limites, o que permite que viva no mundo real, um mundo que é regido por uma legislaçâo que, como lembra Freitas (2002), nos permite viver em grupo. Para que isso ocorra, a lei do pai, segundo o autor, mostra à criança que vários "nãos" serão necessários e deverão ser aceitos.

Porém muitas vezes esses "nãos", que são necessários e devem ser aceitos, são inexistentes na realidade do jovem. Logo, a criança ou o adolescente vai em busca dessa interdição em outros lugares e, como um sinal de esperança, como é levantado por Winnicott (1956/2000), manifesta-se a tendência antissocial.

\section{$O$ adolescente em conflito com a lei}

Winnicott (1956/2000) explica que, quando ocorre a tendência antissocial, aconteceu uma de-privaçáo, que seria a perda de algo bom que a criança experienciou. $\mathrm{Na}$ de-privação a retirada ultrapassa o período em que a criança consegue manter viva a experiência na memória.

A tendência antissocial implica em esperança, como coloca Winnicott (1956/ 2000): uma criança de-privada tem como característica principal a esperança de reencontrar ou encontrar esse algo bom perdido. Nos momentos em que ainda se manifesta a esperança na vida dessa criança ela manifesta a tendência

Psic. Clin., Rio de Janeiro, vol. 25, N.I, P. 37 - 52, 2013 
antissocial. Winnicott (1999) também afirma que uma característica da tendência antissocial é o impulso do adolescente de tentar voltar ao momento que antecedeu a privação.

O roubo, segundo Winnicott (1956/2000), está no centro da tendência antissocial. Ele não seria a tentativa de obter o objeto roubado, mas sim algo a que o jovem tem direito; no caso da criança seria a busca pela mãe que, criada por ela, pela sua criatividade primária, lhe pertence e deverá ser encontrada. Seria procurar algo em outros lugares, depois de ter fracassado em um lugar anterior: um ato de esperança.

Selosse (1998, citado por Araújo, 2006) entende o gesto transgressor como decorrente de uma carência primitiva e uma falta fundamental. Araújo (2006) ainda reflete a partir de Selosse (1998) que o adolescente tenta cobrar a "dívida" que a vida tem com ele por meio da transgressão.

Vivemos em grupos sociais e para a boa convivência nesses grupos é necessário um estabelecimento de normas. Freitas (2002) explica que a lei não é para humilhar ou submeter o ser humano, ela existe justamente para regular as condiçóes para o convívio em grupo, mostrando o que pode ou náo ser feito e aceito. $\mathrm{O}$ autor coloca que os adolescentes que não encontram limites internos para suas fantasias destrutivas vão procurar em algum lugar essa interdição, buscam em algum lugar o limite, um não definitivo, podendo se destruir ao longo dessa busca.

É interessante refletir com Winnicott (1982/1992) sobre o movimento que o adolescente faz. $\mathrm{O}$ autor sustenta que quando a criança perde os limites que a continham ela não está liberta; ao contrário, está presa numa busca incessante por estes. Maia (2001) expressa bem que nessa procura o jovem cada vez mais estica seus braços para encontrar a mãe que um dia o conteve e não o contém mais.

Araújo (2006) também observa essa busca da criança e do adolescente uma vez que se veem privados do referencial paterno, partindo para os espaços sociais. Discutindo a tendência antissocial, a autora reflete sobre o gesto de esperança de ser "visto" na família e na sociedade e lembra que muitas vezes a justiça tem ocupado esse espaço, tornando-se o limite e a possibilidade de visibilidade para o adolescente.

O autor (Araújo, 2006) lembra que quem acolhe e reconhece o adolescente se torna o "pai" e, como comentamos anteriormente, esse "pai" pode ser o traficante, a rua, as gangues, qualquer um que ofereça o que este adolescente está procurando: ser alguém no mundo.

Às vezes uma arma proporciona ao adolescente ser alguém, ser visto e querido por um grupo, o que não foi conseguido em outros contextos, inclusive na família. Sudbrack (1992) diz que o adolescente transpóe em ato o que 
não consegue converter em palavras. Seria um apelo ao pai, uma busca pela lei. Goldenberg (1998, citada por Araújo, 2006) afirma que a transgressão do adolescente é uma forma de conseguir da sociedade um controle, através de medidas de execução.

Araújo (2006) nos lembra ainda que devemos ter em mente os sentidos assumidos no ato transgressor, o que significa, para o jovem, o que esse ato traz para ele como influência na sua construção identitária.

\section{Lei simbólica e função paterna no contexto jurídico}

O Estatuto da Criança e do Adolescente (ECA) foi criado pela Lei $n^{\circ}$ 8069, de 13 de julho de 1990, adotando a Doutrina da Proteção Integral, gerando uma verdadeira transformação paradigmática, pois substituiu o Código de Menores de 1979, até entáo em vigor.

A Doutrina de Proteção Integral fundamenta-se na concepçáo de que a criança e o adolescente são sujeitos de direitos frente à família, à sociedade e ao Estado. Deixam de ser simples objetos de intervenção no mundo e, como lembram Marçura, Cury e Paula (2002), passam a ser "titulares de direitos", bem como de direitos especiais decorrentes da condição peculiar de pessoas em processo de desenvolvimento. Desenvolvimento este, como completa Machado (2003), físico, psíquico e emocional.

O ECA trouxe a definição de ato infracional, estando previsto em seu artigo 103: "Considera-se ato infracional a conduta descrita como crime ou contravenção penal” (ECA, Art. 103).

Definindo o que seria ato infracional o ECA considera o infrator como uma categoria jurídica; logo, um possuidor de direitos e deveres. Por serem considerados inimputáveis, os adolescentes não sofrem processo criminal e tampouco são punidos criminalmente. Logo, em se tratando das definiçôes acima, os adolescentes, à luz do ECA, são destituídos desse prisma de criminosos ou contraventores, uma vez que são menores de dezoito anos de idade e, assim, inimputáveis como pessoas em desenvolvimento. Amaral e Silva (2002, citado por Saraiva, 2002) sustenta que o ECA criou um regime jurídico que eleva o adolescente à dignidade de responder por seus atos, diferindo das penas criminais por seu aspecto predominantemente pedagógico.

A inimputabilidade, como aponta Chesani Júnior (2005), não pode ser confundida com irresponsabilidade. Os adolescentes, mesmo sendo considerados pessoas em desenvolvimento, são responsabilizados pelos seus atos, de acordo com o que é imposto pelo ECA.

Psic. Clin., Rio de Janeiro, vol. 25, N.I, P. 37 - 52, 2013 
Pereira (2008) reforça essa diferenciação entre inimputabilidade e responsabilidade, lembrando que o focado nas medidas socioeducativas é o aspecto pedagógico, o que não anula a "faceta punitiva" das medidas.

Entre essas medidas socioeducativas há uma divisão entre medidas não privativas de liberdade e as privativas de liberdade. As medidas não privativas de liberdade, como indica o ECA em seu artigo 112, constituem-se em advertência, reparação de dano, prestação de serviço à comunidade e a liberdade assistida.

Já as medidas privativas de liberdade, consideradas mais rigorosas, são o Regime de Semiliberdade e a Internação. Volpi (2002, p. 28) sustenta que "a restrição de liberdade deve significar apenas limitação do exercício pleno do direito de ir e vir e não de outros direitos constitucionais, condição para sua inclusão na perspectiva cidadâ".

Compartilhamos com Araújo (2006) a ideia de que a intervenção judicial representa uma "esperança" para o adolescente e sua família, sendo uma possibilidade de reorganização psíquica e social, gerando assim uma mudança de estilo de vida. Seria aqui o "Pai Jurídico" de Araújo (2006, p. 18), "aquele que é representado por uma Instituição que atua em nome da Lei", o que impóe o limite, a lei simbólica, a esse adolescente e à sua família, permitindo-lhes estruturar as leis e se reorganizarem dentro da sociedade.

Concordamos com a afirmação de Saraiva $(2003$, p. 88$)$ sobre não haver "cidadania sem responsabilidade e não pode[r] haver responsabilização sem o devido processo e o rigor garantista”. Sudbrack (2002) lembra que instituição jurídica, além de exercer para o adolescente a interdição do pai repressor, também representa açôes de garantia de proteção e de exercício da cidadania.

Araújo (2006), ao analisar o trabalho da Justiça, elabora a partir de seu contato com Juízes e Promotores sobre a solidão relatada por estes no trabalho com os adolescentes em conflito com a lei. A autora discute sobre como é fácil imputar a responsabilidade ao outro, porém a ideal aplicação do ECA deve se dar pela mãos dos Juízes, assim como dos poderes excecutivo, legislativo e de toda a sociedade civil.

\section{Metodologia}

No presente artigo, utilizamos como referência epistemológica e metodológica a epistemologia qualitativa de González Rey (2005). Com sua epistemologia qualitativa o autor propóe uma forma de satisfazer às exigências epistemológicas inerentes ao estudo da subjetividade como constitutiva do indivíduo e das suas diferentes formas de organização social. 
Como afirma o autor (González Rey, 2005), pensar a subjetividade pressupóe superar um conjunto de dicotomias entre o social-individual, interno-externo, mente-corpo. Assim, a epistemologia qualitativa se apresenta como uma busca de produção de conhecimento que pretende estudar a subjetividade humana em sua realidade plurideterminada, diferenciada, irregular, interativa e histórica.

A epistemologia qualitativa privilegia a significação do singular para a produçấo de conhecimento; logo, o sujeito é visto como único na sua constituição subjetiva, e a legitimidade do conhecimento não está na quantidade de pessoas estudadas e sim na qualidade de expressão de cada sujeito (González Rey, 2006).

Para a presente pesquisa foram visitadas algumas instituiçôes de trabalho com adolescentes em conflito com a lei, sendo elas a Promotoria de Defesa da Infância e Juventude do Distrito Federal e Territórios e a Defensoria Pública do Distrito Federal.

Utilizamos como instrumento a entrevista semidirigida, visando conhecer o universo do objeto pesquisado, assim como a construçáo subjetiva do mesmo.

A pesquisa foi realizada com 2 sujeitos, sendo 1 Promotora da Promotoria de Defesa da Infância e Juventude do DF e 1 Defensor Público da Defensoria Pública do DF. Os sujeitos foram acionados e convidados a participarem da pesquisa; os mesmos eram livres para deixar de participar da pesquisa a qualquer momento, conforme informado em Consentimento Livre e Esclarecido.

Dados pessoais e que possam comprometer os sujeitos pesquisados não serão fornecidos.

\section{Construção de informaçáo}

\section{A representação da lei simbólica e função paterna para instituiçôes de auxílio a adolescentes em conflito com a lei}

Concordamos com Ciarallo (2004) que afirma que compreender a aplicação da lei não se atendo a todas as instituiçôes envolvidas é compreender de maneira incompleta todo o processo que envolve o adolescente em conflito com a lei. Assim, mesmo sendo o Juiz o personagem decisivo nesse processo, as outras instituiçôes estão presentes, atuantes e têm sua importância no processo.

Como todos os atores veem os adolescentes em conflito com a lei é parte essencial do processo e dos resultados que se obterão junto a esses adolescentes. Cézar Freitas (2001) lembra que crianças e adolescentes são apresentados no pro-

Psic. Clin., Rio de Janeiro, vol. 25, N.I, P. $37-52,2013$ 
cesso a partir de uma narrativa do profissional envolvido - logo, as expectativas para os resultados futuros tornam-se subordinadas às consideraçóes expressas por esses profissionais.

A imagem que os atores entrevistados têm sobre os adolescentes em conflito com a lei é de sujeitos envolvidos em um processo muito mais profundo do que a simples ação infracional. Em sua fala, o Defensor Público entrevistado coloca que "normalmente quando nos chegam, esses adolescentes em conflito com a lei são todos aqueles que estão refletindo uma disfunção familiar. Essa disfunção advém de violência, muitos casos de violência familiar e envolvimento com drogas".

Podemos entender que, antes do envolvimento com os atos infracionais, o adolescente tem toda uma história que antecede esse conflito com a lei. E não é só o fator econômico que leva esses adolescentes à criminalidade, a Promotora entrevistada deixa claro quando diz que

hoje em dia a gente não vê mais aquele adolescente em conflito com a lei que vem de uma camada financeira menos beneficiada. A gente já vê muitos jovens de classe média envolvidos com essa situação. Então são várias circunstâncias que a gente vê no dia-a-dia de atuação da Promotoria que levam o adolescente a se envolver com atos infracionais.

A família, que deveria fazer parte do processo de desenvolvimento do adolescente com aquele "algo especial" que Winnicott (1997) aborda, muitas vezes é ausente na vida desses jovens.

Ao serem encaminhados à Defensoria, por exemplo, os adolescentes muitas vezes vão sozinhos, completamente desassistidos pela família e, mesmo sendo processados, muitas vezes a família por muito tempo é omissa. Até então o contato com a família é muito pouco, o contato maior é com o adolescente. Tem a primeira audiência, onde eles são orientados sobre os procedimentos que vão ocorrer. Alguns pais nos procuram outros não procuram, entáo quer dizer, fica uma coisa muito tênue. Normalmente o contato é muito maior quando eles recebem a medida de internação... (Defensor Público).

Além de se sentirem abandonados pela família, os adolescentes têm o sentimento de náo serem ninguém, de serem um nada na sociedade. Como expressa o Defensor, eles "foram excuídos da sociedade", e consideramos que alguns deles nem ao menos existiram para essa sociedade. Esse fato reflete a visibilidade dis- 
cutida por Araújo (2006), o gesto de esperança para ser visto na família e na sociedade. Ser invisível, um ninguém, pode ser uma fórmula para a marginalidade. Refletindo sobre a tendência antissocial analisada por Winnicott (1956/2000), a partir desse sentimento de abandono e invisibilidade, o jovem tenderia a procurar formas de ser visto e "existir" na sociedade. Trata-se, então, da busca do reconhecimento e da interdição da lei paterna.

Compreender o sentido dado ao exercício da função paterna como lei simbólica pelos atores da justiça envolvidos no trabalho com adolescentes em conflito com a lei nos permite vislumbrar possibilidades de trabalhar com esses adolescentes, respeitando o apelo pedagógico da Justiça da Infância e Juventude e, claro, respeitando os limites dos atores em questão.

Propusemos uma metáfora entre o trabalho dos atores da justiça e o exercício da função paterna, lembrando que a função paterna é a responsável por apresentar o limite que, como sugere Winnicott (2000), é estruturador da criatividade e sua ausência dificulta a organização da subjetividade do jovem.

Os motivos da ausência da funçáo paterna são variados e nem sempre por falta dos genitores, mas por estes não representarem figuras identificatórias para os filhos. Nem sempre o pai consegue ser o representante da lei e transmiti-la para seu filho de forma que o adolescente internalize essa lei.

Quando do encontro do adolescente com os atos infracionais, a justiça vem como representante da lei e consideramos que mesmo que em um primeiro momento represente uma função de repressão, de interdição, a justiça também representa a possibilidade de o jovem ser visto, ser responsabilizado pelo ato infracional cometido, ter a possibilidade de ser inserido na sociedade e ser reconhecido como sujeito.

O Defensor entrevistado reconhece como a Justiça pode se tornar um representante da função paterna, frente a essa realidade globalizada. "A Instituição Jurídica exerce a função paterna para esses adolescentes, uma função substitutiva" (Defensor Público). Essa visão de "função substitutiva" remete à discussão sobre a função paterna ser um lugar, uma figura que, de acordo com Freitas (2002), permite uma organização da subjetividade da criança e do adolescente.

O Defensor ainda coloca - sobre a metáfora de a Justiça exercer uma função paterna para os adolescentes em conflito com a lei -, que é algo "muito interessante, o conceito da função paterna, porque às vezes o pai e a mãe falam e falam e não tem nenhum efeito, aí você coloca um terceiro e ele é ouvido e pode ter muito efeito". Vislumbramos nesta fala do Defensor um pai que exerce mais que o corte na simbiose mãe-bebê, pois seria um pai que Araújo (2006) aponta como facilitador das separaçóes e que impulsiona o adolescente a seguir em frente, oferecendo uma fonte de limite e identificação e uma possibilidade de reinserção na sociedade.

Psic. Clin., Rio de Janeiro, vol. 25, N.I, P. 37 - 52, 2013 
Essa possibilidade de reinserção na sociedade vem da confiança que a referência paterna proporciona. Como Araújo (2006) coloca, quando o adolescente tem essa referência ele usa da criatividade para construir um espaço de ilusão na construção do real.

Ao discutir a tendência antissocial, Araújo (2006) reflete sobre como o jovem busca a visibilidade na família e na sociedade e como a justiça exerce o limite e a possibilidade de visibilidade quando o jovem se envolve em atos infracionais. Identificamos na fala do Defensor como a Defensoria Pública permite essa visibilidade. "Aplicada a medida, ele continua vinculado à Defensoria Pública. Existe o núcleo socioeducativo, ele continua vinculado; até que cumpra até o fim a medida ele é acompanhado pela Defensoria" (Defensor).

Discutindo ainda a tendência antissocial, podemos lembrar como Winnicott (1956/2000) propóe que um possível tratamento para a tendência antissocial seria o fornecimento de um ambiente que cuida, que permite ser redescoberto pela criança. Consideramos essa posição muito próxima do que é feito pela Defensoria: acolher o adolescente em conflito com a lei e permitir que ele se expresse e seja visto sem que tenha que recorrer a atos infracionais - mais que acolher e permitir a visibilidade, muitas vezes a justiça assume um papel de educadora, o que tem toda uma ligação com a atividade interditora e protetora.

\footnotetext{
Então é muito comum estarmos em audiência e perguntar ao jovem se fez uso de alguma substância no dia, e eles dizem que usaram rupinol, com maconha, cocaína e não sei mais o quê. E eles estão se expondo muito, porque essa mistura toda, todo mundo sabe que é uma coisa tão grave que pode gerar uma taquicardia, uma coisa assim. Então a gente alerta muito pra isso, apesar de a gente não ser especialista nessa área, mas essas coisinhas corriqueiras do dia-a-dia a gente acaba passando pra eles, justamente para servir de alerta, de como ele deu sorte de estar vivo, porque a mistura pode causar graves problemas e aí nessas ocasiôes a gente precisa encaminhar para um acompanhamento (Promotora).
}

Esse comportamento da Promotora mostra como, além da repressão pelos atos infracionais cometidos, existe uma preocupação com a reorganização do adolescente. Há a tentativa de fazê-lo enxergar a gravidade dos seus atos e como seu futuro pode estar comprometido com suas atitudes. Mostrar que eles são responsáveis: como lembra Chesani Júnior (2005), eles são inimputáveis, mas isso não os faz irresponsáveis. Os atores da Justiça representam esse papel de educador seja aplicando uma medida socioeducativa, seja mostrando as consequências de um envolvimento com drogas por exemplo. 
Com relação à família, a Promotora afirma que nem sempre a família vem. Muitas vezes a família não vem porque não toma conhecimento ou até o adolescente é um adolescente de rua, às vezes realmente tem uma família mas está morando na rua e não tem contato com a família, então não tem meios de conseguirmos localizá-la. Outras vezes a família tem o conhecimento e o adolescente já deu tanto problema que eles não querem vir. Já vieram outras vezes e dizem que não virão mais. E a gente sempre nos plantóes, a gente tenta entrar em contato com a família, então sempre indaga aos jovens se têm telefone da mãe, de um vizinho próximo e aí passando esse contato a gente mesmo tenta esse contato, até pra informar que o jovem está aqui, o que aconteceu, se ele vai permanecer internado ou não, e também indagar sobre o comportamento do jovem. (Promotora).

Mais uma vez é o "Pai Jurídico" (Araújo, 2006) que atua como lei simbólica não só com o adolescente, mas com toda sua família, a fim de integrar essa rede e fazer o adolescente ser e se sentir pertencente a esse grupo.

A Promotora diz que a postura do Promotor é a mesma dos outros atores que atuam nessa área:

todo mundo busca a mesma coisa, a gente quer ressocializar esse jovem, recuperar esse jovem, mostrar que o caminho não é esse, que existe um outro caminho diferente, só que infelizmente a gente aqui e mais especificamente na área infracional, a gente fica um pouco de mãos atadas, porque a gente não trabalha nem na política pública, nem na execução da medida socioeducativa.

Esse sentimento de mãos atadas me remete ao que Araújo (2006) discute sobre a solidão que os atores da justiça sentem. E ainda mais, a Promotora coloca que sua atuação é

um pouco frustrante, porque o que eu estou fazendo, acompanhando o processo todo desde o começo, eu cumpri o meu papel quando eu tomei ciência que foi aplicada a ele uma medida de liberdade assistida? Por um lado eu cumpri, mas por outro eu não cumpri, porque infelizmente, dependendo da localidade em que ele reside aqui no Distrito Federal, não vai acontecer nada, a medida não funciona, não tem agente, então a liberdade assistida é muito falha, infelizmente no Distrito Federal é essa a realidade. Fora algumas satélites onde há um acompanhamento, há um engajamento da sociedade, há a execução

Psic. Clin., Rio de Janeiro, vol. 25, N.I, P. 37 - 52, 2013 
dessa liberdade assistida, mas na grande maioria não há. Então, cumpri meu papel? Não, não cumpri meu papel. Então pelo menos eu na minha atuação prezo muito pela conversa com ele e com a família, eu acho que o momento mais importante é aquele momento em que ele está na minha frente, onde eu tento passar um recado, passar uma orientação e é uma coisa rara mas às vezes a gente consegue, uma orientação, uma conversa, um puxão de orelha bem dado a gente consegue que caia a ficha desse adolescente (Promotora).

Consideramos que essa falha na execução das medidas poderia ser trabalhada com um envolvimento maior da sociedade e uma cobrança pela implementação de políticas públicas. Compartilhamos com Saraiva (2002) que a omissão tanto do Estado quanto da sociedade leva a distorçôes na operacionalização das medidas e, logo, impede a reparaçấo do adolescente pelo seu ato e a sua inserção na sociedade.

Pensando nessa realidade na execução das medidas e na carência no Distrito Federal, a Promotora apresenta uma medida socioeducativa exclusiva do DF, a Visita ao CAJE.

Nós aqui no DF criamos uma modalidade diferente de medida socioeducativa, nós criamos a Visita ao CAJE, não existe essa medida socioeducativa no Estatuto. E a Visita ao CAJE por incrível que pareça tem surtido um resultado muito positivo, porque aqui na conversa a gente já adverte, "olha, se você continuar nesse meio você pode ir lá pro CAJE cumprir uma medida de internação, é isso que você quer pra você?”' . Aí muitos quando fazem a visita, digamos assim, "cai a ficha" (Promotora).

Essa ida ao CAJE consiste em o adolescente, junto com seu responsável, fazer uma visita à instituiçấo e elaborar uma redação sobre o que viu, e essa redação é anexada ao processo. A Promotora entrevistada diz que, frente à carência do DF, são exigidos projetos paralelos que levem a sociedade a se mobilizar e pressionar o Estado para que medidas sejam executadas e aconteça a implementação do ECA.

Entendemos que, enquanto um representante da função paterna, da lei simbólica, os atores entrevistados encaixam-se no papel tanto de pai repressor quanto protetor. Protetor enquanto se fundamenta na Doutrina de Proteção Integral, quando em seu trabalho a prioridade é o adolescente e sua ressocialização, reconhecimento como sujeito e, como lembram Marçura et al. (2002), trabalha para que eles passem a ser titulares de direitos e deveres. 
Às vezes representamos o pai, porque é muito comum pegarmos adolescentes que não têm família, e na verdade, o que podemos fazer aqui, a visão deles muitas vezes, eles chegam aqui dizendo que quem pode ajudá-los somos nós, o Ministério Público, e aqui nós tentamos fazer tudo o que é possível. Então o Ministério Público, especificamente aqui na Infância, acho que tem esse papel sim, de tentar puxar as rédeas daquele menino e tentar dar um encaminhamento na vida daquele menino (Promotora).

Esse "puxar as rédeas" seria mais uma vez uma forma de possibilitar que o adolescente se reorganize, psíquica e socialmente, e tenha a esperança que Araújo (2006) aponta como representada pela açáo judicial. Com os atores entrevistados, identificamos a preocupação em, além de proporcionar aos adolescentes essa esperança, acompanhá-los e garantir que, com a ajuda desse "Pai Jurídico" (Araújo, 2006), os adolescentes em conflito com a lei reparem seus atos e se ressocializem, tendo além do apoio da Justiça também o apoio da família, que também é apoiada pela Justiça.

\section{Conclusóes}

Acreditamos que o envolvimento com atos antissociais é resultado de um processo que envolve várias etapas e que infelizmente culmina num ato infracional. E é muito importante a visão da Promotora entrevistada ao fazer questão de romper com o preconceito de muitos sobre a origem do adolescente em conflito com a lei. "Hoje em dia não vê mais aquele adolescente em conflito com a lei que vem de uma camada financeira menos beneficiada".

Quer dizer, o fator econômico náo é o causador de um adolescente em conflito com a lei. Entendemos que a motivaçâo para a entrada no mundo infracional é realmente a falta daquele "algo especial" que Winnicott (1997) nos lembra, que a família possui e que auxilia no cuidado com o filho. Apesar disso, infelizmente, no Brasil a grande população em medida de internação é proveniente da classe menos favorecida economicamente.

Identificamos na fala da Promotora como a Promotoria vai além da figura do pai repressor; sua atuação é em busca da ressocialização do adolescente em conflito com a lei, mas "infelizmente a gente aqui e mais especificamente na área infracional, a gente fica um pouco de mãos atadas, porque a gente não trabalha nem na política pública, nem na execução da medida socioeducativa" (Promotora).

Psic. Clin., Rio de Janeiro, vol. 25, N.I, P. $37-52,2013$ 
Entendemos aqui como cada setor tem suas limitaçóes e como é difícil ir adiante sem o apoio de todos, assim como é necessária a participação da sociedade, que deveria estar presente nas ações públicas, e também dos outros atores da justiça, que muitas vezes não se comunicam, o que dificulta o trabalho com o adolescente em conflito com a lei. A resposta que encontramos para a frustração relatada pela Promotora é um maior diálogo entre os órgãos públicos que trabalham com os adolescentes em conflito com a lei e, claro, o envolvimento da sociedade, que se daria a partir de políticas de divulgação do trabalho desses órgãos e um trabalho de prevenção, que incluiria a educação e a motivação para a mobilização da sociedade.

Os atores entrevistados passaram a reconhecer a figura paterna que exercem para os adolescentes em conflito com a lei e suas famílias. Postura que a Promotora entende como educadora, acolhedora e preocupada com o futuro do jovem, e que "tenta fazer tudo que é possível... tudo o que está a nosso alcance" (Promotora).

Identificamos nesses atores a preocupação de mostrar para esses adolescentes que a esperança que Araújo (2006) discute é real e eles têm uma chance na vida, que podem encontrar na justiça não só um repressor para seus atos, mas o (a)braço, que, de acordo com Maia (2001), os conterá e lhes permitirá se reorganizarem e se tornarem sujeitos.

\section{Referências}

Araújo, S. M. B. (2006). Pai, aproxima de mim esse cálice: significaçōes de Juizes e Promotores sobre a Função Paterna no contexto da Justiça (Tese de Doutorado, Curso de Pós-graduação em Psicologia Clínica, Universidade de Brasília, Brasília, DF).

Cézar Freitas, M. (2001). Para uma sociologia histórica da infância no Brasil. In: C. F. Marcos (org.). História da infância no Brasil (pp. 11-18). São Paulo: Cortez.

Chesani Júnior, F. (2005) A prescrição e o ato infracional. (Monografia. Curso de Bacharel em Ciências Jurídias, Universidade de Caxias do Sul, Rio Grande do Sul, RS). Recuperado em 22 de março, 2009, de <www.mp.rs.gov.br/areas/infancia/arquivos/infracionalprescricao.doc. >.

Ciarallo, C. R. C. A. (2004). A Justiça em conflito com a lei: retratos do adolescente no processo judicial. (Dissertação de Mestrado. Curso de Pós-graduação em Psicologia Clínica, Universidade de Brasília, Brasília, DF).

Dor, J. (1991). O pai e sua função em psicanálise. Rio de Janeiro: Jorge Zahar Editor.

Freitas, L. A. P. (2002). Adolescência, família e drogas. A função paterna e a questão dos limites. Rio de Janeiro: MAUAD.

Psic. Clin., Rio de Janeiro, vol. 25, N.I, P. 37 - 52, 2013 


\section{2 - Representação da função paterna para instituições}

Estatuto da Criança e do Adolescente. (1990). Brasília.

González Rey, F. L. (2005). Pesquisa qualitativa em psicologia: caminhos e desafios. São Paulo: Thomson-Pioneira.

González Rey, F. L. (2006). As representaçôes sociais como produção subjetiva: seu impacto na hipertensão e no câncer. Psicologia: Teoria e Prática, 8(2), 69-85.

Julien, P. (1997). O manto de Noé. Rio de Janeiro: Revinter.

Machado, M. T. (2003). A proteçâo constitucional de crianças e adolescentes e os Direitos Humanos. São Paulo: Manole.

Maia, M. V. C. M. (2001). Pode alguém comer seu próprio bolo e continuar a possuí-lo? Universitas Psicologia - Revista de Psicologia da Faculdade de Ciências da Saúde do Centro Universitário de Brasília - UniCEUB, 02(02). 279-287.

Marçura, J. N., Cury, M. \& Paula, P. A. G. (2002). Estatuto da Criança e do Adolescente anotado. São Paulo: RT.

Pereira, L. A. V. (2008). A prescrição das medidas sócio-educativas. Revista IOB de Direito Penal e Processual Penal, São Paulo, 50, 7-14.

Saraiva, J. B. C. (2002). Adolescente e ato infracional - Garantias processuais e medidas sócio-educativas. Porto Alegre: Livraria do Advogado.

Saraiva, J. B. C. (2003). Adolescente em conflito com a lei - da indiferença à proteção integral. Porto Alegre: Livraria do Advogado.

Sudbrack, M. F. O. (1992). Da falta do Pai à busca da Lei - O significado da passagem ao ato delinquente no contexto familiar e institucional. Revista Psicologia: Teoria e Pesquisa, 8 (supl), 447-457.

Sudbrack, M. F. O. (2002). Autoridade e figura paterna: reflexóes a partir da psicologia clínica, da psicossociologia e a psicanálise. Revista Tribunal de Justiça do Distrito Federal e Território, 2(2), 39-44.

Volpi, M. (2002). O adolescente e o ato infracional. São Paulo: Cortez.

Winnicott, D. W. (2000). A tendência anti-social. In: Da pediatria à psicanálise: obras escolhidas (pp. 406-416). Rio de Janeiro: Imago (Trabalho original publicado em 1956).

Winnicott, D. W. (1992). Aspectos da delinquência juvenil. In: A criança e seu mundo (pp. 182-193). Rio de Janeiro: Guanabara Koogan (Trabalho original publicado em 1982).

Winnicott, D. W. (1997). A família e o desenvolvimento individual. São Paulo: Martins Fontes. Winnicott, D. W. (1999). Tudo começa em casa. São Paulo: Martins Fontes.

Recebido em 23 de setembro de 2012 Aceito para publicaçấo em 24 de março de 2013

Psic. Clin., Rio de Janeiro, vol. 25, N.I, P. 37 - 52, 2013 